\title{
The effect of nutrition on the neural mechanisms potentially involved in melatonin-stimulated LH secretion in female Mediterranean goats
}

\author{
Luis A Zarazaga, Irma Celi, José Luis Guzmán and Benoît Malpaux \\ Department of Agroforestry Sciences, University of Huelva, Carretera de Palos de la Frontera s/n, Palos de la Frontera, 21819 Huelva, Spain \\ ${ }^{1}$ Physiologie de la Reproduction et des Comportements, UMR INRA-CNRS-Université de Tours-Haras Nationaux, Centre INRA de Tours, 37380 Nouzilly, France \\ (Correspondence should be addressed to L A Zarazaga; Email: zarazaga@uhu.es)
}

\begin{abstract}
This research examines which neural mechanisms among the endogenous opioid, dopaminergic, serotonergic and excitatory amino acid systems are involved in the stimulation of LH secretion by melatonin implantation and their modulation by nutritional level. Female goats were distributed to two experimental groups that received either $1 \cdot 1$ (group $\mathrm{H} ; n=24$ ) or $0 \cdot 7$ (group $\mathrm{L} ; n=24$ ) times their nutritional maintenance requirements. Half of each group was implanted with melatonin after a long-day period. Plasma LH concentrations were measured twice per week. The effects of i.v. injections of naloxone, pimozide, cyproheptadine and $\mathrm{N}$-methyl-D,L-aspartate (NMDA) on LH secretion were assessed the day before melatonin implantation and again on days 30 and 45 . The functioning of all but the dopaminergic systems was clearly modified by the level of nutrition, melatonin implantation and time elapsed since
\end{abstract}

implantation. Thirty days after implantation, naloxone increased LH concentrations irrespective of the level of nutrition $(P<0 \cdot 05)$, similar to NMDA in the melatoninimplanted $\mathrm{H}$ goats (HM; $P<0 \cdot 01)$. On day 45 , naloxone increased LH concentrations in the HM animals $(P<0 \cdot 05)$, similar to cyproheptadine in both the non-implanted $\mathrm{H}(\mathrm{HC})$ and the HM animals $(P<0 \cdot 01)$. Finally, at 45 days, NMDA increased the LH concentration in all subgroups $(P<0 \cdot 01)$. These results provide evidence that the effects of different neural systems on LH secretion are modified by nutritional level and melatonin implantation. Endogenous opioids seem to be most strongly involved in the inhibition of $\mathrm{LH}$ secretion on days 30 and 45 after melatonin implantation. However, the serotonergic mechanism appears to be most influenced by nutritional level.

Journal of Endocrinology (2011) 211, 263-272

\section{Introduction}

Nutrition is thought to be an important factor affecting the reproductive function in domestic ruminants, influencing the onset of ovarian cyclicity in goats (Walkden-Brown et al. 1994, Zarazaga et al. 2005). Low levels of food intake or poor body condition are associated with enhanced hypothalamic sensitivity to oestradiol (Rhind et al. 1991, Rhind 1992). In Mediterranean goats, nutrition can modulate the effect of photoperiod on the length and depth of seasonal anoestrus (Zarazaga et al. 2005) and undernutrition induces lower LH concentrations during short and long days (Zarazaga et al. $2011 a, b)$. But in undernourished sheep, or those with low body condition scores (BCS), melatonin implantation allows a high ovulation rate (Forcada et al. 1995, Rondón et al. 1996) and a large number of healthy cleaved oocytes and blastocyst rate to be obtained (Vázquez et al. 2009, 2010).

Melatonin regulates seasonal reproduction through changes in the pulsatile secretion of GNRH and LH (Bittman et al. 1985, Viguié et al. 1995a). Its action on the activity of GNRH neurones appears to be indirect. A number of studies have suggested that different neurotransmitters are involved in the

regulation of LH secretion by melatonin or photoperiod, especially in ewes (Meyer \& Goodman 1985, 1986, Le Corre \& Chemineau 1993, Forcada et al. 1997). The neuroendocrine mechanism downstream of the action of melatonin, leading to the regulation of $\mathrm{LH}$ secretion, appears to involve several dopaminergic structures in the hypothalamus, such as the A14 and A15 nuclei of the lateral retrochiasmatic area (Havern et al. 1994) and the arcuate nucleus-median eminence region (Anderson et al. 1997). In sheep, serotonin receptors are thought to be involved in the neural mechanisms that regulate the release of $\mathrm{LH}$ associated with the photoperiod. In this species, the determination of the brain-binding sites of the tritiated 5-hydroxytryptamine receptor $_{2}\left(5 \mathrm{HT}_{2}\right)$ antagonist ketanserin led to the identification of a specific ventral hypothalamic zone in which the binding density parallels the change in LH pulsatility (Le Corre et al. 1994). In goats, it has recently been shown that inhibitory pathways, such as the endogenous opioid pathways, regulate $\mathrm{LH}$ secretion during the early inhibition of LH secretion by long days and during LH stimulation by short days. Further, the dopaminergic inhibitory pathways are responsible for a reduction in $\mathrm{LH}$ pulse frequency during the 
onset of LH inhibition by long days and during the inhibition of LH secretion by long days. Finally, the serotonergic system is involved during the onset of $\mathrm{LH}$ inhibition by long days, in the inhibition of LH secretion by long days, and in the onset of LH stimulation by short days, but always in well-nourished females (Zarazaga et al. 2011a).

The excitatory amino acids (EAA), glutamate and aspartate, are major stimulatory neurotransmitters in the mammalian nervous system. Acting through $\mathrm{N}$-methyl-D,L-aspartate (NMDA) receptors, in sheep, these amino acids modulate the secretion of LH (Estienne et al. 1990, Lincoln \& Wu 1991). In support of this, the administration of NMDA, a glutamatergic receptor agonist, acutely stimulates $\mathrm{LH}$ secretion (Viguié et al. 1995b). This stimulatory effect is larger during the period of photoinhibition of LH secretion than during the photostimulation, suggesting that EAA are involved in the photoperiodic regulation of LH secretion (Lincoln \& Wu 1991). In bucks, the stimulatory effect of NMDA on LH secretion is more pronounced when subjected to long days than short days (Gazal et al. 2002). However, the information available on the effect of neuroexcitatory amino acid receptors in $\mathrm{LH}$ secretion in melatonin-implanted goats, or goats subjected to different levels of nutrition, is lacking.

Continuing our previous research (Zarazaga et al. 2011a), the present research assesses the interaction between the nutritional level and melatonin implants on the regulation of LH secretion by the endogenous opioid, dopaminergic, serotonergic and NMDA systems in melatonin-implanted Mediterranean goats maintained under a long-day photoperiod.

\section{Materials and Methods}

\section{Study conditions}

All procedures were performed by trained personnel in strict accordance with Spanish guidelines for the protection of experimental animals (RD 1201/2005) and in agreement with European Union Directive 86/609. The study was conducted at the University of Huelva experimental farm (latitude $37^{\circ} 15^{\prime} \mathrm{N}$ ), which meets the requirements of the European Community Commission for Scientific Procedure Establishments (1986).

\section{Animals, nutrition, photoperiod and melatonin treatments}

The study animals were 48 adult female goats. All were ovariectomised 1 month before beginning the experiment and simultaneously implanted subcutaneously with a $3 \cdot 0 \mathrm{~cm}$ Silastic implant (internal diameter $3.3 \mathrm{~mm}$ and external diameter $4.6 \mathrm{~mm}$; Karsch et al. 1973) containing crystalline oestradiol (Sigma-Aldrich Chemical Co.). These implants were soaked in physiological serum before insertion to prevent an initial peak of steroid release.
The experiment had a $2 \times 2$ factorial design (two nutrition levels, plus implantation - or not - of exogenous melatonin). Doses assigned to two experimental groups were based on the provision of nutrition balanced for live weight (LW) and BCS (Hervieu et al. 1991). The members of the high-nutrition group (group $\mathrm{H} ; n=24$ ) were fed $700 \mathrm{~g}$ concentrate and $500 \mathrm{~g}$ barley straw each day, while the members of the lownutrition group (group L; $n=24$ ) received $350 \mathrm{~g}$ concentrate and $500 \mathrm{~g}$ barley straw. These amounts correspond to a daily intake of 0.78 milk fodder units (UFL) and $100 \mathrm{~g}$ digestible protein (group $\mathrm{H}$ ) and $0.49 \mathrm{UFL}$ and $50 \mathrm{~g}$ digestible protein (group L), providing 1.1 and 0.7 times the maintenance requirements of a goat with an $\mathrm{LW}$ of $50 \mathrm{~kg}$ at the beginning of the experiment, according to the INRA standards (Morand-Fehr \& Sauvant 1988). The concentrate was offered once a day, distributed individually; the barley straw was distributed loosely to each group. The concentrate was a commercial mixture of maize $(26 \cdot 3 \%)$, beans $(20 \%)$, oats $(14 \cdot 1 \%)$, cotton-seed $(13 \cdot 7 \%)$, peas $(13 \cdot 4 \%)$, lupin $(7 \cdot 3 \%)$, barley $(0 \cdot 2 \%)$, wheat $(0 \cdot 2 \%)$, sunflower seeds $(0 \cdot 2 \%)$ and a commercial mineral-vitamin complement (4.6\%). All the animals had free access to water and mineral blocks containing trace elements and vitamins.

Both groups were housed in a lightproof building under artificial lighting where they were exposed for 9 months to alternations between 3 months of long days (16 h of light/day; lights-on: $0700 \mathrm{~h}$, lights-off: $2300 \mathrm{~h}$ ) and 3 months of short days (8 h of light/day; lights-on: $0700 \mathrm{~h}$, lights-off: $1500 \mathrm{~h}$ ). The first 3 months of controlled photoperiod (long days, started on September 14th) was necessary for the animals to adapt to the experimental conditions. The next 3 months (short days) were deemed necessary to ensure that the animals were able to respond to a stimulatory photoperiod prior to melatonin insertion. The final phase of long days was required before melatonin could be implanted.

At the end of the second period of long days (June 14th), each nutritional group was divided into two subgroups, i.e. those that received a melatonin implantation (18 mg; Melovine, CEVA Salud Animal, Barcelona, Spain) at the base of the left ear (M) and those that did not (C): HM $(n=12)$ and HC $(n=12)$, and LM $(n=12)$ and LC $(n=12)$. After the implantation procedure, all animals were maintained under a long-day photoperiod to ensure that the positive effect of the melatonin implants on $\mathrm{LH}$ secretion was due to exogenous melatonin.

\section{Sampling and measurements}

The effect of photoperiod treatments on neuroendocrine LH activity was assessed through monitoring long-term plasma LH variations, collecting blood samples twice per week by jugular venipuncture at $0930 \mathrm{~h}$. The samples were immediately centrifuged for $30 \mathrm{~min}(3000 \mathrm{~g})$ and the plasma stored at $-20^{\circ} \mathrm{C}$ until use. The time of onset of LH secretion after melatonin implantation was determined for each animal as differing from the baseline by more than 3 s.D. The baseline 
was defined as the mean value of the samples obtained from May 2 until June 13 - the period with the lowest LH concentrations (Fig. 1). The LW and BCS of all animals were recorded weekly.

To evaluate the melatonin concentrations induced by the implants, five weekly blood samples were taken from each goat during the light phase, starting 1 week after melatonin implantation.

\section{Drugs}

Antagonists to opioid receptors (naloxone), dopaminergic 2 receptors (pimozide), serotonin $5 \mathrm{HT}_{2}$ receptors (cyproheptadine) and an agonist of neuroexcitatory amino acid receptors (NMDA) were administered at different time points during the stimulation of $\mathrm{LH}$ secretion by the melatonin implantation. Naloxone hydrochloride (Sigma-Aldrich Chemical Co.) was dissolved in $0.9 \%(\mathrm{w} / \mathrm{v})$ sterile saline at a concentration of $4.8 \mathrm{mg} / \mathrm{ml}$. Pimozide (Sigma-Aldrich Chemical Co.) was dissolved in $0 \cdot 1 \mathrm{M}$ tartaric acid at a
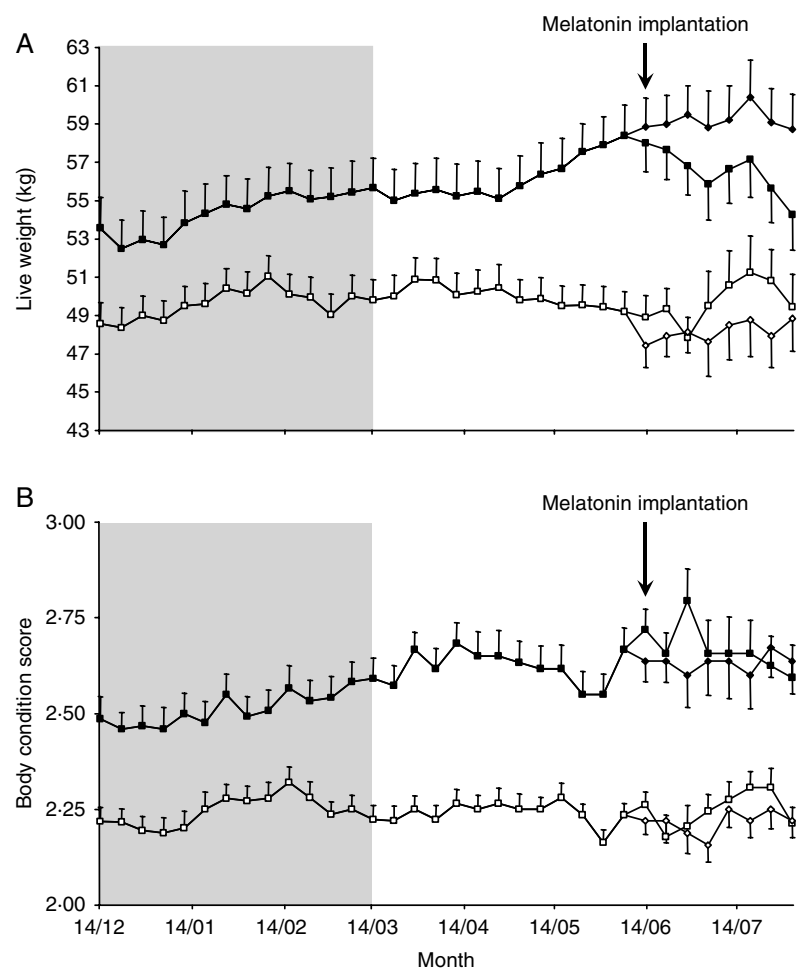

Figure 1 Changes (mean \pm S.E.M.) in live weight (A) and body condition score (B) in Mediterranean female goats subjected to alternations of 3 months of short days and 3 months of long days that received $1 \cdot 1$ (solid symbols, $n=24$ ) or $0 \cdot 7$ (open symbols, $n=24$ ) times their maintenance requirements, respectively, and that were implanted (filled square, $n=12$; open square, $n=12$ ) or not (filled diamond, $n=12$; open diamond, $n=12)$ with melatonin $(14 / 06)$. Shaded areas indicate the months when animals were exposed to short days. concentration of $3 \mathrm{mg} / \mathrm{ml}$. Cyproheptadine hydrochloride sesquihydrate (Sigma-Aldrich Chemical Co.) was dissolved in $50 \%$ ethanol-propanediol at a concentration of $25 \mathrm{mg} / \mathrm{ml}$. NMDA, comprising a mixture of $\mathrm{D}$ and $\mathrm{L}$ isomers (SigmaAldrich Chemical Co.), was dissolved in $0.9 \%$ sterile and apyrogenic saline at a concentration of $5 \mathrm{mg} / \mathrm{ml}$. Each drug was dissolved $<3 \mathrm{~h}$ before i.v. injection and stored at room temperature until use. All drugs were administered as a bolus into the jugular vein though a catheter.

\section{Drug challenges}

Preliminary experiment: NMDA dose-response curve A dose-response curve for the effect of NMDA on LH secretion was created in a preliminary experiment to determine the dosage to be used in the main experiment. This preliminary work was performed on three animals of group $\mathrm{H}$ (before randomisation for implantation). LH secretion in these animals was inhibited by exposure to 70 long days $(16 \mathrm{~h}$ light: $8 \mathrm{~h}$ darkness cycle) during the second period of long days. Three doses were tested at $48 \mathrm{~h}$ intervals on the same animals (1, 2 and $4 \mathrm{mg} / \mathrm{kg} \mathrm{BW}$ ) in increasing order. $\mathrm{LH}$ secretion was assessed in serial samples of jugular blood obtained every $10 \mathrm{~min}$ during the hour preceding the injection, and every $10 \mathrm{~min}$ for $2 \mathrm{~h}$ thereafter.

For the other drugs, doses similar to those used by Zarazaga et al. (2011a) were given: $2 \mathrm{mg} / \mathrm{kg}$, and originally 0.6 and $0.6 \mathrm{mg} / \mathrm{kg} \mathrm{LW}$ for naloxone, pimozide and cyproheptadine respectively. The latter two doses were reduced by $0.15 \mathrm{mg} / \mathrm{kg}$ since ataxia and akinesia symptoms were seen in $20 \%$ of the animals $3 \mathrm{~h}$ after the $0.6 \mathrm{mg} / \mathrm{kg}$ pimozide injection, and respiratory depression was observed in about $40 \%$ of animals after the $0.6 \mathrm{mg} / \mathrm{kg}$ cyproheptadine injection. No correlation was seen between these side effects and the $\mathrm{LH}$ responses to drug treatments.

Main experiment: the effects of naloxone, pimozide, cyproheptadine and NMDA on $\mathrm{LH}$ release in goats at different time points following melatonin implantation The first drug challenge was given during the inhibition of LH secretion by long days before the melatonin implantation (day -1). The second challenge was given before the onset of $\mathrm{LH}$ increase, on day 30. The third challenge was given when LH secretion was stimulated by the melatonin implantation, on day 45. At each time, all goats of each subgroup (HC, HM, LC and LM) were distributed in balanced 'drug groups' according to the LW and BCS. Each animal, from each 'drug group', received naloxone and then NMDA after 5 days $(n=6)$, or cyproheptadine and then pimozide after 5 days (using the other six females), the 5-day period allowing for washout of the previously administered drug. Drugs were always administered in the same order. As a consequence, each goat of each subgroup received two drugs, naloxone and NMDA or cyproheptadine and pimozide. During all drug challenges, blood samples were collected via jugular catheter at $10 \mathrm{~min}$ intervals $3 \mathrm{~h}$ before (control period) 
and $3 \mathrm{~h}$ after (drug period) the i.v. injection of the drug or corresponding vehicle (controls). The sampling periods started at $0900 \mathrm{~h}$ and finished at $1500 \mathrm{~h}$.

\section{Hormone assays and LH pulse identification}

Plasma LH concentrations were determined using double antibody ELISA, as described by Faure et al. (2005). The sensitivity of the assay was $0 \cdot 1 \mathrm{ng} / \mathrm{ml}$. The intra- and interassay coefficients of variation (CV) in the control were 6.5 and $3 \cdot 0 \%$ respectively. All samples from the same challenge were measured in the same assay.

LH pulses were defined according to Baird et al. (1981) as the point with two consecutive values higher than the two preceding ones, with the highest value (pulse amplitude) exceeding the mean baseline value by at least four times the $\mathrm{CV}$ of the assay.

Plasma melatonin concentrations were measured by RIA in duplicate aliquots of $100 \mu \mathrm{l}$ blood plasma (Fraser et al. 1983), using the antibody first raised by Tillet et al. (1986). The sensitivity of the assay was $4 \mathrm{pg} / \mathrm{ml}$. The intra-assay CV was $5 \cdot 83 \%$.

All hormonal analyses were conducted at the hormone analysis laboratory at the Centre INRA de Tours, Nouzilly, France.

\section{Statistical analysis}

The data obtained during the first 3 months of the study (September 14th to December 14th) were excluded from the statistical analysis since they referred to the period needed by the animals to adapt to the sheds and nutritional treatments. The effects of nutrition on LW and BCS (measured weekly) and LH concentrations (measured twice weekly) were analysed using one-way ANOVA (nutritional treatments: groups $\mathrm{H}$ or $\mathrm{L}$ ) with time as a repeated measure. Two-way ANOVA was used to determine the effect of nutrition plus melatonin treatment on $\mathrm{LH}$ secretion, with time as a repeated measure.

The mean LH concentrations and mean LH pulse frequencies and amplitudes in the drug treatments were calculated for each pre- and post-administration period. Due to the non-parametric nature of the LH pulse frequency, a Wilcoxon test was performed for between-dose comparisons of the effect of NMDA on the number of LH pulses. The effects of the treatments on mean LH concentration were analysed using a paired $t$-test (pre- vs post-injection periods).

Mean LH concentrations during the pre- and postinjection periods at each time point in the stimulation of the $\mathrm{LH}$ secretion by the melatonin treatment $(-1,30$ and 45 day after melatonin insertion) were compared using ANOVA, with drug (naloxone, pimozide, cyproheptadine or NMDA), nutrition level ( $\mathrm{H}$ or $\mathrm{L}$ ), melatonin implantation (or not) and time as repeated measures. The Tukey test was performed when differences between drug treatments were significant. After ANOVA, the effect of the drug treatments on mean LH concentration were analysed using a paired $t$-test (pre- vs post-injection periods) at each time point before and after melatonin implantation, and for each nutritional group.

Due to the non-parametric nature of $\mathrm{LH}$ pulse frequency, the Kruskal-Wallis ANOVA test was used to examine the differences between the HL, HM, LC and LM subgroups before drug injection. After ANOVA, the effects of drug treatments on the number of LH pulses were analysed using the Wilcoxon test (pre- vs post-injection periods) for each time point studied before and after melatonin implantation, and for each drug before and after its administration within each nutritional subgroup.

Significance was set at $P<0 \cdot 05$. All calculations were performed using the SPSS package (Statistical Package for the Social Sciences 2008).

\section{Results}

\section{$L W$ and $B C S$}

Before melatonin implantation, mean LW and BCS varied substantially over time in both group $\mathrm{H}$ and group $\mathrm{L}$ animals $(P<0 \cdot 05$; Fig. 1), but with mean LW and BCS higher in the former $(55.9 \pm 0.3 \mathrm{~kg}$ and $2.59 \pm 0.01$ vs $49.5 \pm 0.3 \mathrm{~kg}$ and $2 \cdot 23 \pm 0 \cdot 01)$. After melatonin implantation, LW, but not BCS, varied substantially over time in all groups (HC, HM, LC and LM; $P<0 \cdot 01)$, although no effect of melatonin treatment on LW or BCS was seen, nor was any interaction between sources of variation and time observed $(P>0 \cdot 05)$.

\section{LH concentration profiles}

Nutrition had a significant effect on LH secretion prior to melatonin implantation $(0.65 \pm 0.02$ vs $0.45 \pm 0.01 \mathrm{ng} / \mathrm{ml}$ for the $\mathrm{H}$ and $\mathrm{L}$ groups respectively; $P<0 \cdot 01$; Fig. 2 ).

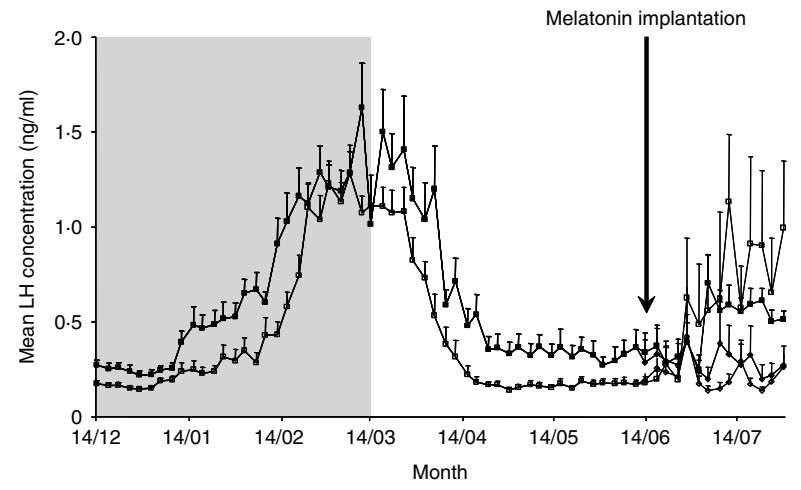

Figure 2 Changes (mean \pm S.E.M.) in plasma LH concentration $(\mathrm{ng} / \mathrm{ml})$ in Mediterranean female goats subjected to alternations of 3 months of short days and 3 months of long days that received $1 \cdot 1$ (solid symbols, $n=24$ ) or $0 \cdot 7$ (open symbols, $n=24$ ) times their maintenance requirements, respectively, and that were implanted (filled square, $n=12$; open square, $n=12$ ) or not (filled diamond, $n=12$; open diamond, $n=12$ ) with melatonin (14/06). Shaded areas indicate the months when animals were exposed to short days. 
After melatonin implantation, $\mathrm{LH}$ concentrations increased $(P<0.05$; Fig. 2). An interaction between nutrition and melatonin implantation $(P<0.05)$ affecting $\mathrm{LH}$ secretion was also observed; the LH concentration of the LM animals was clearly higher than that of the HM animals (Fig. 2).

The mean interval between melatonin implantation and the stimulation of $\mathrm{LH}$ secretion was $31 \cdot 3 \pm 3 \cdot 4$ days, with no differences seen between HM and LM animals. Only three goats from the HC and LC groups, which were maintained under long days, showed a slight increase in LH concentration.

\section{Melatonin concentrations}

Melatonin implantation had a clear effect on plasma melatonin concentration $(227 \cdot 1 \pm 28 \cdot 1$ vs $4 \cdot 2 \pm 0 \cdot 1 \mathrm{pg} / \mathrm{ml}$ for implanted and non-implanted animals respectively; $P<0 \cdot 01$ ). Neither nutrition nor the melatonin implantation by nutrition interaction had any effect on melatonin concentration $(P>0 \cdot 05)$.

\section{LH secretion response to NMDA dose (preliminary experiment)}

The injection of NMDA caused an acute increase in LH secretion, characterised by a sustained and prolonged rise in plasma LH levels. This response was dose dependent $(P<0 \cdot 01)$, with mean LH concentrations peaking at $1 \cdot 1$, 1.8 and $2 \cdot 1 \mathrm{ng} / \mathrm{ml}$ for NMDA doses of 1,2 and $4 \mathrm{mg} / \mathrm{kg} \mathrm{BW}$ respectively. After injection of the highest dosage $(4 \mathrm{mg} / \mathrm{kg}$ BW), LH secretion remained above baseline for more than $2 \mathrm{~h}$. This dose was therefore used for the main experiment.

The effect of nutrition and drug treatment on LH secretion on day -1 before melatonin implantation

Figure 3 shows the differences between the pre- and postinjection periods for each nutritional treatment and drug.

Nutrition had a significant effect on mean LH concentration during the $3 \mathrm{~h}$ prior to drug injection $(0 \cdot 32 \pm 0 \cdot 01 \mathrm{vs}$ $0 \cdot 20 \pm 0 \cdot 01 \mathrm{ng} / \mathrm{ml}$ for the $\mathrm{H}$ and $\mathrm{L}$ groups respectively; $P<0 \cdot 05)$ with no variations in concentration during this period irrespective of the drug vehicle injected as a control $(P>0 \cdot 05)$. LH pulsatility was not modified by nutritional level during the pre-injection period $(P>0 \cdot 05)$.

The NMDA treatment induced higher LH concentrations $(P<0 \cdot 001 ; 0 \cdot 73 \pm 0.05 \mathrm{ng} / \mathrm{ml})$ and pulsatility $(P<0 \cdot 05)$ in both the $\mathrm{L}$ and $\mathrm{H}$ groups, especially in the former. Cyproheptadine increased LH concentration $(P<0 \cdot 01)$ and pulsatility $(P<0 \cdot 05)$ only in the $\mathrm{H}$ group animals.

\section{The effect of nutrition, melatonin and drug treatment on $\mathrm{LH}$ secretion on day 30 after melatonin implantation}

Figure 4 shows the differences in LH secretion between the pre- and post-injection periods for each nutritional subgroup (HM, HC, LM and LC) and drug.
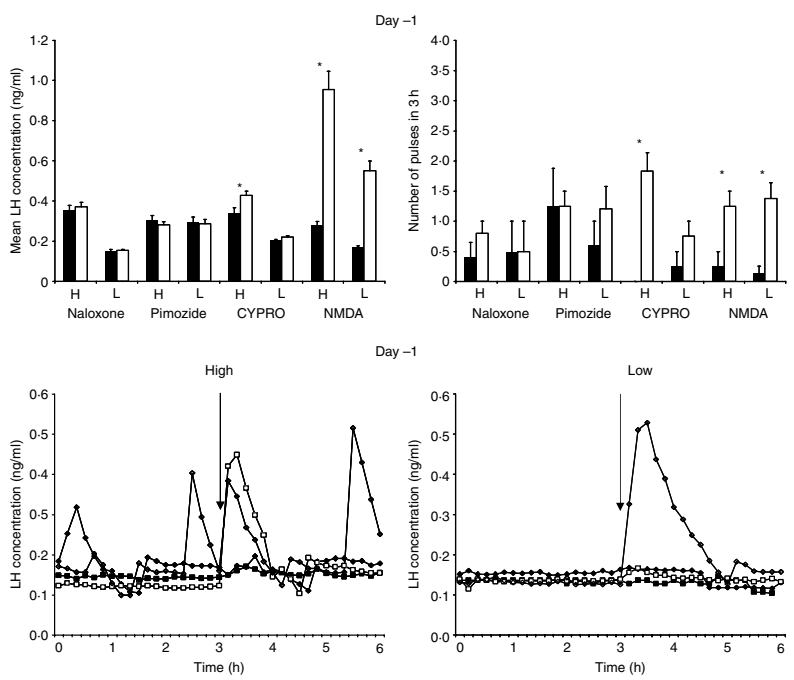

Figure 3 Effect of naloxone, pimozide, cyproheptadine and NMDA on mean plasma LH concentrations ( \pm s.E.M., top left panel) and on the mean number of $\mathrm{LH}$ pulses in the $3 \mathrm{~h}$ ( \pm S.E.M., top right panel) period before (filled square) and after (open square) injection, on the day before melatonin insertion (day -1$)$, into female Mediterranean goats that received $1 \cdot 1$ ( $\mathrm{H}$ group, $n=24)$ or $0 \cdot 7$ times their maintenance requirements (L group, $n=24$ ). Six goats per drug were used for each experimental group. A representative profile of an ovariectomised oestradiol-treated dose-administered naloxone (filled square), pimozide (filled diamond), cyproheptadine (open square) or NMDA (open diamond) is shown at the bottom. The arrows indicate the time of the drug injection. ${ }^{*} P<0 \cdot 05$.

Prior to drug injection, no effect of nutrition was seen on LH secretion (a difference between the HC and LC groups was no longer observed due to the melatonin implantation by nutrition interaction). At this time, neither the melatonin implantation nor the drug vehicles, injected as controls, had any effect on LH secretion $(P>0 \cdot 05)$. However, LH pulsatility was affected by nutritional level $(0 \cdot 52 \pm 0 \cdot 12$ vs $1 \cdot 23 \pm 0 \cdot 27$ pulses for the $\mathrm{H}$ and $\mathrm{L}$ groups respectively; $P<0 \cdot 05)$, but not by melatonin.

During the post-injection period, naloxone increased the LH concentration in the HM $(P<0 \cdot 01)$ and LM animals $(P<0 \cdot 05)$, and NMDA increased the LH concentrations in the HM and HC subgroups $(P<0 \cdot 01)$. The injection of both naloxone and NMDA increased the mean number of $\mathrm{LH}$ pulses in the HM animals $(P<0 \cdot 05)$.

\section{The effect of nutrition, melatonin and drug treatments on LH secretion in goats on day 45 after melatonin insertion}

Figure 5 shows the differences in $\mathrm{LH}$ secretion between the pre- and post-injection periods for each nutritional subgroup (HM, HC, LM and LC) and drug.

During the $3 \mathrm{~h}$ period prior to drug injection, no effect of nutrition on LH secretion was observed (again probably due to the melatonin implantation by nutrition interaction; $P>0.05)$, although both melatonin implantation $(0.52$ \pm 0.02 vs $0 \cdot 26 \pm 0 \cdot 01 \mathrm{ng} / \mathrm{ml}$ for the $M$ and $C$ groups 


\section{Day 30}

A

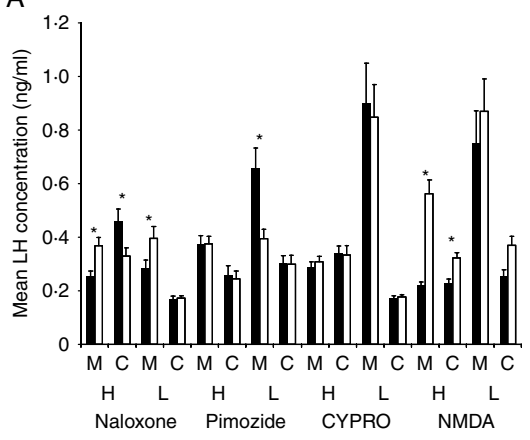

C
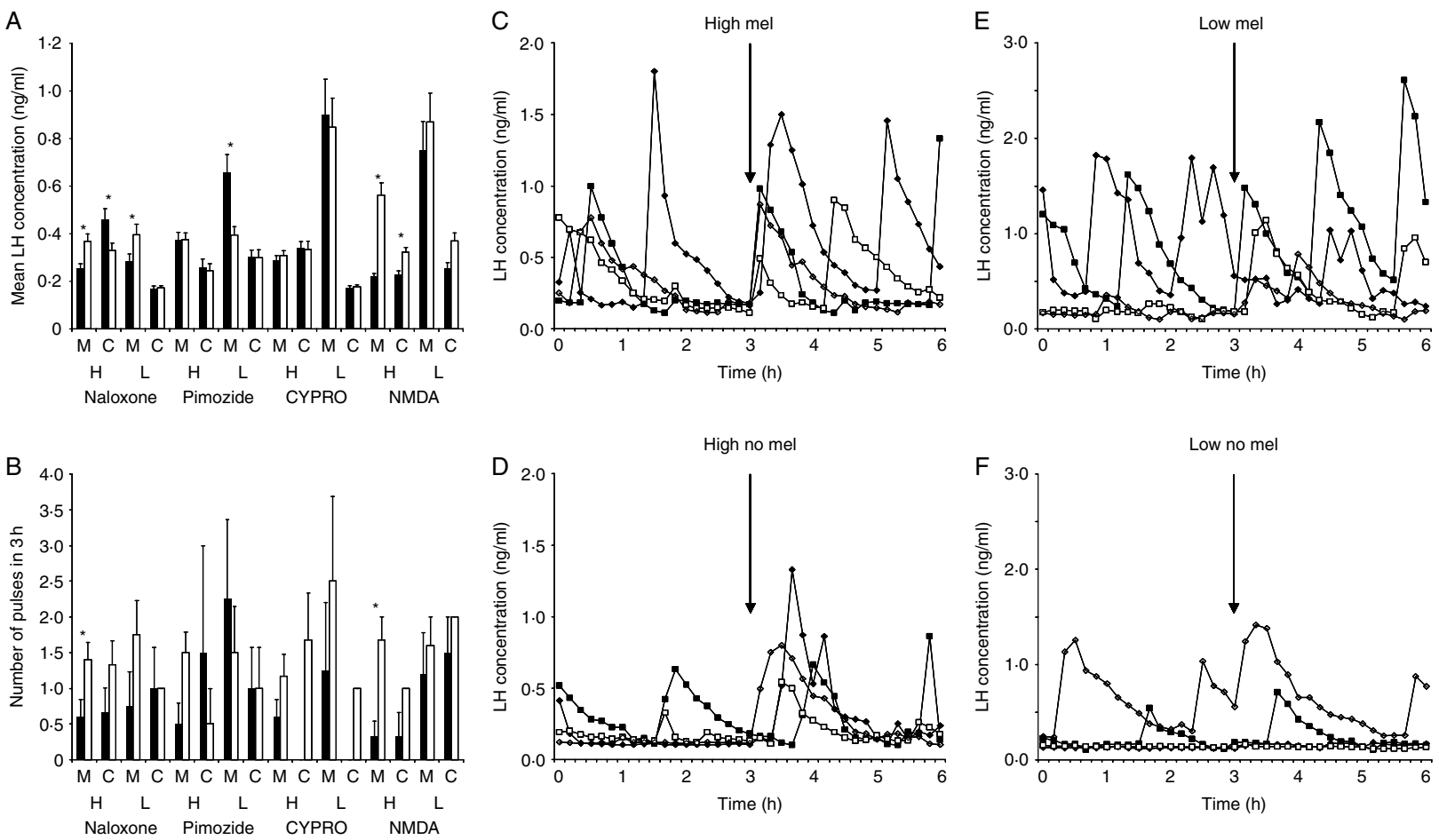

Figure 4 Effect of naloxone, pimozide, cyproheptadine and NMDA at $30 \mathrm{~d}$ after melatonin insertion on mean plasma LH concentration ( \pm S.E.M., A), and on the mean number of LH pulses, in the $3 \mathrm{~h}$ ( \pm S.E.M., B) period before (filled square) and after (open square) injection into female Mediterranean goats that received 1.1 ( $\mathrm{H}$ group, $n=24)$ or 0.7 times their maintenance requirements $(\mathrm{L}$ group, $n=24)$, and that were implanted $(\mathrm{M})$ or not $(\mathrm{C})$ with melatonin. Six goats per drug were used for each experimental subgroup. A representative profile of an ovariectomised oestradiol-treated dose-administered naloxone (filled square), pimozide (filled diamond), cyproheptadine (open square) or NMDA (open diamond) is shown in C, D, E and F. The arrows indicate the time of the drug injection. ${ }^{*} P<0 \cdot 05$.

respectively; $P<0 \cdot 05)$ and the melatonin implantation by nutrition interaction $(0 \cdot 32 \pm 0 \cdot 01,0 \cdot 34 \pm 0 \cdot 02,0 \cdot 70 \pm 0 \cdot 04$ and $0 \cdot 21 \pm 0 \cdot 01 \mathrm{ng} / \mathrm{ml}$ for the HM, HC, LM and LC groups respectively; $P<0 \cdot 01)$ had a significant effect. The different drug vehicles injected during this period as controls had no effect on LH secretion either $(P>0 \cdot 05)$. However, LH pulsatility was affected by the level of nutrition $(0 \cdot 80 \pm 0 \cdot 15 \mathrm{vs}$ $1 \cdot 33 \pm 0.18$ pulses for the $\mathrm{H}$ and $\mathrm{L}$ groups respectively; $P<0 \cdot 05)$ and melatonin implantation $(1 \cdot 30 \pm 0 \cdot 16$ vs $0 \cdot 70$ $\pm 0 \cdot 15$ pulses for the $\mathrm{M}$ and $\mathrm{C}$ groups respectively; $P<0 \cdot 05$ ).

Naloxone only increased the LH concentration in the HM group $(P<0 \cdot 05)$. Cyproheptadine increased LH concentrations in the HM and HC groups $(P<0 \cdot 01)$. NMDA clearly increased $\mathrm{LH}$ concentrations in all experimental groups $(P<0 \cdot 01)$. However, LH pulsatility was only increased by cyproheptadine in the HM and HC groups $(P<0 \cdot 05)$.

\section{Discussion}

In this study, before the implantation of melatonin, the lower level of nutrition induced a reduction in the mean $\mathrm{LH}$ concentration independent of the photoperiod, as reported in previous work by our group (Zarazaga et al. 2011a). These results help explain earlier findings that a low BCS induced by a low level of nutrition (De Santiago-Miramontes et al. 2009), or a maintenance level of nutrition compared to a higher level of nutrition (Zarazaga et al. 2005), induced a longer seasonal anoestrus as a result of an earlier onset of the anovulatory period. The reason for this may be that, as seen in this study, hypothalamic-pituitary activity is diminished in animals with reduced levels of nutrition. This reduction in LH associated with a lower nutritional level contrasts with that reported by Meza-Herrera et al. (2008), who suggest that the increased ovarian activity observed with undegradable protein supplementation, and in goats with better body conditions, is not the result of changes in $\mathrm{LH}$ or $\mathrm{GH}$. Rather these authors suggest an effect at local level caused by changes in insulin in a non-GNRH-gonadotrophin-dependent manner. The reason for this discrepancy could be that these authors studied $\mathrm{LH}$ concentrations only around the periovulatory period. Similarly, Kouakou et al. (2008), working with dairy bucks subjected to underfeeding and refeeding, observed that neither underfeeding nor the transition to ad libitum feeding affected LH concentrations. Moreover, in this study, the LH concentrations observed before melatonin implantation were 
A
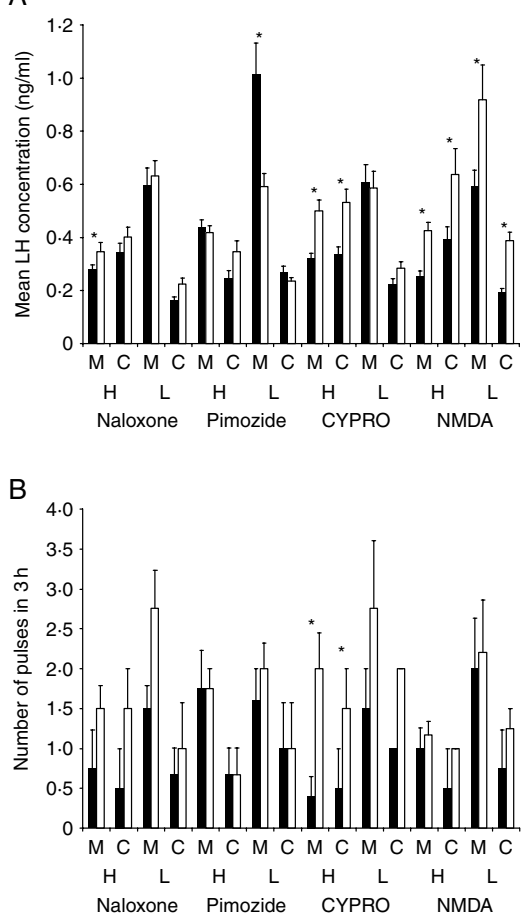

Day 45
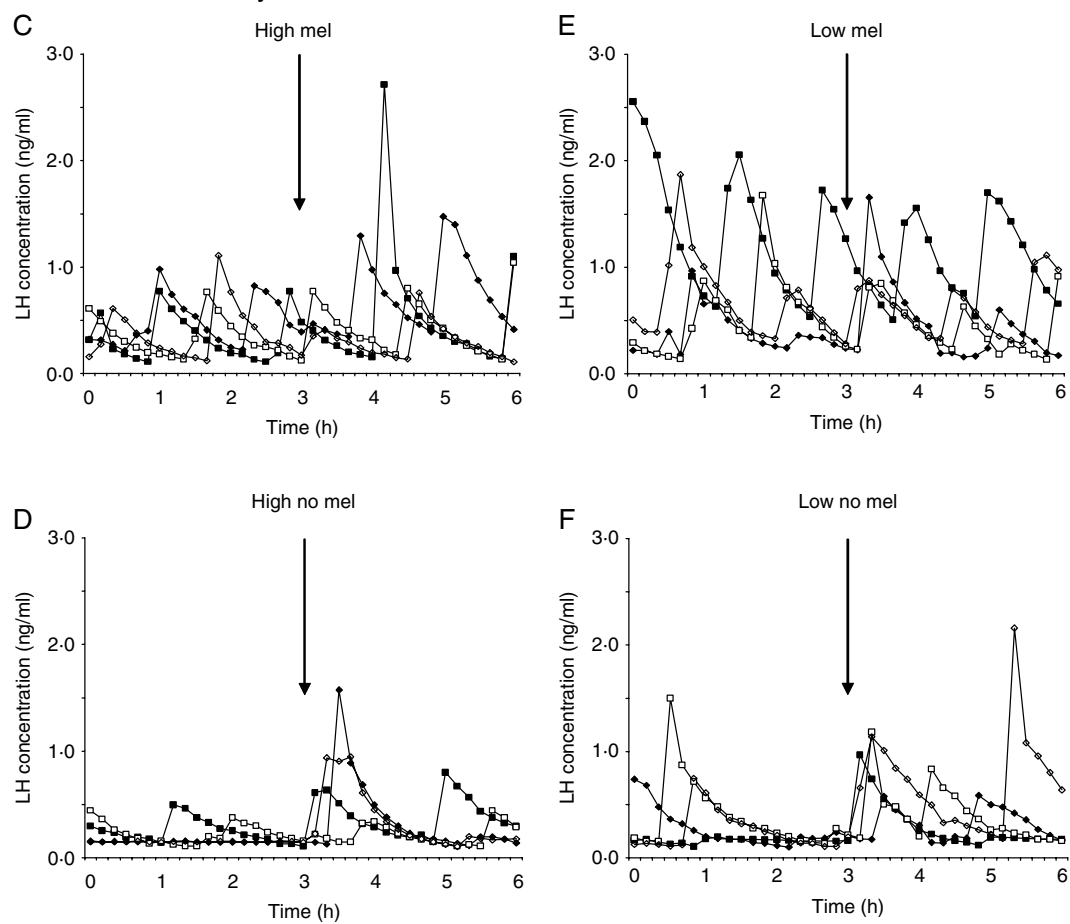

Figure 5 Effect of naloxone, pimozide, cyproheptadine and NMDA at $45 \mathrm{~d}$ after melatonin insertion on mean plasma LH concentration ( \pm S.E.M., A), and on the mean number of LH pulses, in the $3 \mathrm{~h}$ ( \pm s.E.M., B) period before (filled square) and after (open square) injection into female Mediterranean goats that received $1 \cdot 1$ (H group, $n=24$ ) or $0 \cdot 7$ times their maintenance requirements $(\mathrm{L}$ group, $n=24)$, and that were implanted $(M)$ or not $(C)$ with melatonin. Six goats per drug were used for each experimental subgroup. A representative profile of an ovariectomised oestradiol-treated dose-administered naloxone (filled square), pimozide (filled diamond), cyproheptadine (open square) or NMDA (open diamond) is shown in C, D, E and F. The arrows indicate the time of the drug injection. ${ }^{*} P<0 \cdot 05$.

similar to those described in OVX +E Mediterranean goats (Zarazaga et al. 2011a), confirming that, in caprines at this latitude, the photoperiod is the main environmental factor controlling pituitary activity but that nutrition is an important modulator of LH secretion.

After melatonin implantation, the LH concentration increased and the onset of pituitary activity was earlier than in non-implanted females. The period between implantation and the activation of pituitary activity $(31 \cdot 3 \pm 3 \cdot 4$ days $)$ was similar to that recorded in previous work when melatonin was implanted at the spring equinox $(30 \cdot 33 \pm 10 \cdot 17$ days; Zarazaga et al. 2009) or after a long-day photoperiod treatment $(29 \cdot 7 \pm 10 \cdot 2$ days; Zarazaga, Gatica, Celi, Guzmán unpublished data), but shorter than that described by Chemineau et al. (1986) who observed no ovulation after a period of 70 short days. This discrepancy is probably due to breed differences and/or lactation influences. The present results also contrast with those obtained in sheep, in which melatonin implantation around the spring equinox does not induce reproductive activity during seasonal anoestrus in $\mathrm{OVX}+\mathrm{E}$ females that have no contact with males (Forcada et al. 2002), or in intact females in contact with males (Forcada et al. 1995).
The melatonin implantation by nutrition interaction had a significant effect on LH secretion. To our knowledge, this is the first report of such an observation in goats. However, in sheep, this interaction (Robinson et al. 1991, Forcada et al. 1995), and the BCS by melatonin implantation interaction (Rondón et al. 1996) have been reported to affect ovulation rate. All these authors report the enhancing effect of melatonin implantation on the ovulation rate to be more pronounced in ewes with a low, rather than a high, feed intake. The practical implications of this interaction could be important in induced reproductive activity during seasonal anoestrus in goats that have suffered reduced food availability.

On the day before melatonin implantation, during the inhibition of LH secretion by the long-day photoperiod, differences were seen in response to the drug challenges compared to that previously reported by our group (Zarazaga et al. 2011a). In our earlier study, pimozide and cyproheptadine increased the LH concentration during the inhibition of LH by long days, but in this study, pimozide had no such effect. The reason for this discrepancy might be that, in the present experiment, the injected doses of both pimozide and cyproheptadine were smaller than those in the previous study by $0 \cdot 15 \mathrm{mg} / \mathrm{kg}$. 
The response to the naloxone injection before melatonin implantation suggests that endogenous opioids are not involved in the inhibition of LH secretion by long days since no response was observed, as previously reported (Zarazaga et al. 2011a). The injection of NMDA increased the $\mathrm{LH}$ concentration in both the $\mathrm{H}$ and $\mathrm{L}$ groups, indicating that nutritional level does not modify the response to EAA and that this mechanism is involved in $\mathrm{LH}$ secretion during the period of its photo-induced inhibition (Lincoln \& Wu 1991).

On day 30 after melatonin implantation, naloxone increased LH secretion irrespective of the level of nutrition, and on day 45 in the HM subgroup. In a previous study (Zarazaga et al. 2011a), in goats exposed to alternations of 3 months of long days and 3 months of short days, increases in LH were also seen, although the drug challenge was given at 55 days after the onset of short days. The present results suggest that stimulation by the endogenous opioid system might occur earlier in well-nourished females or that melatonin implantation more strongly represses the opioid mechanism that inhibits LH secretion than that achieved by artificial short days. In support of this, in ewes, Misztal \& Romanowicz (2005) observed that the stimulatory effect of melatonin or naloxone on $\mathrm{LH}$ secretion was more effective when they were infused intracerebroventricularly in combination. A possible explanation is that the secretion of GNRH/LH in response to the exclusion of the inhibitory tone of endogenous opioids becomes intensified by melatonin at the cellular level. Certainly, studies on the pars tuberalis cells have revealed that cAMP is dramatically elevated following simultaneous treatment with adenylate cyclase activators and melatonin (Hazlerigg et al. 1994, Barrett et al. 2003). Melatonin can induce a sensitised response to adenylate cyclase in ovine pars tuberalis cells, in which the receptor for melatonin is endogenously expressed (Barrett et al. 2003). This mechanism is, however, not fully understood. Nevertheless, the increase in the release of $\mathrm{LH}$, evoked by melatonin under the conditions of exclusion of inhibitory opioid tone, reflects the potent induction of gonadotrophic axis activity. Nevertheless, Yang et al. (1989) failed to elevate LH concentration after the injection of WIN-3, an opioid antagonist, into melatonin-implanted or non-implanted control sheep at 5,15 or 25 days after melatonin implantation. Indeed, at 60 days, they only achieved significantly enhanced LH secretion in three melatonin-implanted ewes showing ovarian cyclicity. These authors suggest that melatonin per se, at least at a level sufficient to advance the breeding season, is unlikely to induce reproductive cyclicity by initially switching LH control to an opioid-mediated system.

The lack of effect of pimozide at days 30 and 45 after melatonin implantation agrees with that described in goats exposed to alternations of 3 months of long days and 3 months of short days (Zarazaga et al. 2011a). These results contrast with previous findings by Forcada et al. (2002), who observed an increase in LH pulsatility in both high- and lownutrition OVX $+\mathrm{E}$ ewes treated with melatonin. This might indicate differences between sheep and goats in relation to the role of the dopaminergic system on regulation of the $\mathrm{LH}$ secretion in melatonin-implanted females.

The positive effect of cyproheptadine on day 45 after melatonin implantation on the HM and $\mathrm{HC}$ subgroups indicates that the negative effect of serotonin mechanism on $\mathrm{LH}$ secretion is reduced when stimulation of $\mathrm{LH}$ secretion by good nutrition levels occurs, independent of melatonin implantation. No evidence was found to support the hypothesis that the influence of melatonin on advancing the breeding season might occur via a serotonergic pathway. Moreover, these results agree with those previously reported by our group (Zarazaga et al. 2011a) when cyproheptadine was injected 55 days after the onset of short days. This procedure was only effective at inducing an increase in LH secretion in well-nourished animals. This suggest that the lower hypothalamic sensitivity to the negative feedback effects of oestradiol in goats receiving higher levels of nutrition is mediated, at least during the above 45 and 55 short day periods, by the serotonergic system.

The injection of NMDA acutely stimulated LH secretion in both the HC and the HM dose 30 days after melatonin implantation, and in all subgroups at 45 days. This suggests that, contrary to that described in sheep (Lincoln \& Wu 1991, Viguié et al. 1995b), EAA are involved in LH secretion during periods of both photostimulation and photoinhibition. In fact, NMDA had a significant effect each time it was administered. The origin of this discrepancy between goats and sheep may be double. First, this mechanism may act in a different manner in ewes and goats, and secondly, Viguié $e t$ al. (1995b) studied the effect of NMDA in OVX +E ewes at 39 and 74 days after melatonin implantation - later than in the present experiment. In bucks, Meza-Herrera et al. (2007a) observed no effect on LH secretion of injecting L-glutamine three times per week during increasingly long days. In pre-pubertal goats, it has been shown that the injection of L-glutamine induces the earlier onset of puberty (MezaHerrera et al. 2007b). According to the present results, the absence of any effect of NMDA on LH secretion in either the LM and the LC animals 30 days after melatonin implantation suggests that these EAA neurotransmitters are strongly inhibited by nutrition at this time. Finally, the positive effect observed at 30 days in both the HM and the HC animals, and at 45 days in all subgroups, provides no evidence to support the hypothesis that the influence of melatonin in advancing the breeding season may occur via a glutamatergic pathways.

\section{Conclusions}

To our knowledge, this is the first study to report results on the role of nutrition and the different neural mechanisms involved in the stimulation of LH secretion by exogenous melatonin in goats. The results provide evidence of a clear interaction between nutrition and melatonin and throw light on how the potential neural systems involved in the stimulation of LH secretion by melatonin are modulated by 
nutritional level. Endogenous opioid receptors seem to be involved in this since the injection of naloxone increased $\mathrm{LH}$ concentrations only in melatonin-implanted animals. However, the serotonergic mechanism, as evidenced by the results of the cyproheptadine injection, appears to be most influenced by nutritional level since a clear response was observed 45 days after the moment of melatonin implantation in those animals that received $1 \cdot 1$ times their nutritional maintenance requirements, irrespective of whether they received melatonin or not. Further, the role of dopaminergic mechanisms would seem to be very small when LH is stimulated by exogenous melatonin. Finally, the stimulation of LH secretion by NMDA is strong in goats implanted with melatonin and maintained under photoperiod conditions that inhibit LH secretion. No evidence was found to support the hypothesis that the influence of melatonin in advancing the breeding season may occur via a glutamatergic pathway.

\section{Declaration of interest}

The authors declare that there is no conflict of interest that could be perceived as prejudicing the impartiality of the research reported.

\section{Funding}

This study was supported by Grant AGL2006-01426 from the C.I.C.Y.T. (Spain).

\section{Author contribution statement}

J L G and B M contributed actively in valuable discussion, drafted the paper and critically read the manuscript. I $\mathrm{C}$ contributed to the handling of the animals and recovering data. L A Z designed the study, analysed the data and wrote the paper.

\section{Acknowledgements}

The authors wish to thank the Assay Laboratory of the Station de Physiologie de la Reproduction et des Comportements (INRA, Nouzilly, France) for undertaking the LH and melatonin assays. The authors are also grateful to CEVA Salud Animal, Barcelona, Spain, for providing Melovine implants. We also thank A Burton for revision of the English manuscript.

\section{References}

Anderson ST, Sawangjaroen K \& Curlewis JD 1997 A method for drug infusion into the lateral median eminence and arcuate nucleus of sheep. Journal of Neuroscience Methods 71 169-176. (doi:10.1016/S0165-0270 (96)00139-2)

Baird DT, Swanston IA \& McNeilly AS 1981 Relationship between LH, FSH and prolactin concentration and the secretion of androgens and estrogens by the preovulatory follicle in the ewe. Biology of Reproduction 24 1013-1025. (doi:10.1095/biolreprod24.5.1013)

Barrett P, Schuster C, Mercer J \& Morgan PJ 2003 Sensitization: a mechanism for melatonin action in the pars tuberalis. Journal of Neuroendocrinology 15 415-421. (doi:10.1046/j.1365-2826.2003.00988.x)
Bittman EL, Kaynard AH, Olster DH, Robinson JE, Yellon SM \& Karsch FJ 1985 Pineal melatonin mediates photoperiodic control of pulsatile luteinizing hormone secretion in the ewe. Neuroendocrinology 40 409-418. (doi:10.1159/000124106)

Chemineau P, Normant F, Ravault JP \& Thimonier J 1986 Induction and persistence of pituitary and ovarian activity in the out-of-season lactating dairy goat after a treatment combining a skeleton photoperiod, melatonin and the male effect. Journal of Reproduction and Fertility 78 497-504. (doi:10. 1530/jrf.0.0780497)

De Santiago-Miramontes MA, Malpaux B \& Delgadillo JA 2009 Body condition is associated with a shorter breeding season and reduced ovulation rate in subtropical goats. Animal Reproduction Science 114 175-182. (doi:10.1016/j.anireprosci.2008.09.001)

Estienne MJ, Schillo KK, Hileman SM, Green MA, Hayes SH \& Boling JA 1990 Effect of $N$-methyl-D,L-aspartate on luteinizing hormone secretion in ovariectomized ewes in the absence and presence of estradiol. Biology of Reproduction 42 126-130. (doi:10.1095/biolreprod42.1.126)

Faure MO, Nicol L, Fabre S, Fontaine J, Mohoric N, McNeilly A \& Taragnat C 2005 BMP-4 inhibits follicle-stimulating hormone secretion in ewe pituitary. Journal of Endocrinology 186 109-121. (doi:10.1677/joe.1. 05988)

Forcada F, Zarazaga L \& Abecia JA 1995 Effect of exogenous melatonin and plane of nutrition after weaning on estrous activity, endocrine status and ovulation rate in Salz ewes lambing in the seasonal anestrus. Theriogenology 43 1179-1193. (doi:10.1016/0093-691X(95)00090-U)

Forcada F, Lozano JM, Abecia JA \& Zarazaga LA 1997 Control of luteinizing hormone secretion in ewes by endogenous opioids and the dopaminergic system during short seasonal anoestrus: role of plane of nutrition. Animal Science 65 217-224. (doi:10.1017/S1357729800016520)

Forcada F, Abecia JA, Zúñiga O \& Lozano JM 2002 Variation in the ability of melatonin implants inserted at two different times after the winter solstice to restore reproductive activity in reduced seasonality ewes. Australian Journal of Agricultural Research 53 167-173. (doi:10.1071/AR00172)

Fraser SP, Cowen P, Franklin M, Franey C \& Arendt J 1983 Direct radioimmunoassay for melatonin in plasma. Clinical Chemistry 29 396-397.

Gazal S, Kouakou B, Amoah EA, Barb CR, Barrett JB \& Gelaye S 2002 Effects of $\mathrm{N}$-methyl-D,L-aspartate on $\mathrm{LH}, \mathrm{GH}$, and testosterone secretion bucks maintained under long or short photoperiods. Journal of Animal Science $\mathbf{8 0}$ $1623-1628$.

Havern RL, Whisnant CS \& Goodman RL 1994 Dopaminergic structures in the ovine hypothalamus mediating estradiol negative feed-back in anestrous ewes. Endocrinology 134 1905-1914. (doi:10.1210/en.134.4.1905)

Hazlerigg DG, Hastings MN \& Morgan PJ 1994 The recovery of ovine pars tuberalis cells from melatonin-induced sensitization is slow, protein synthesis-dependent phenomenon. Journal of Endocrinology 142 127-138. (doi:10.1677/joe.0.1420127)

Hervieu J, Morand-Fehr P, Schmidely Ph, Fedele V \& Delfa R 1991 Mesures anatomiques permettant d'expliquer les variations des notes sternales, lombaires et caudales utilisées pour estimer l'état corporel des chèvres laitières. Options Méditerranéennes 13 43-56.

Karsch FJ, Weick RF, Hotchkiss J, Dierschke DJ \& Knobil E 1973 An analysis of the negative feedback control of gonadotropin secretion utilizing chronic implantation of ovarian steroids in ovariectomized rhesus monkeys. Endocrinology 93 478-486. (doi:10.1210/endo-93-2-478)

Kouakou B, Gazal OS, Terrill TH, Kannana G, Gelaye S \& Amoaha EA 2008 Digestibility, hormones and blood metabolites in dairy bucks subjected to underfeeding and refeeding. Small Ruminant Research 75 171-176. (doi:10. 1016/j.smallrumres.2007.10.002)

Le Corre S \& Chemineau P 1993 Control of photoperiodic inhibition of luteinizing hormone secretion by dopaminergic and serotonergic systems in ovariectomized Ile-de-France ewes supplemented with oestradiol. Journal of Reproduction and Fertility 97 367-373. (doi:10.1530/jrf.0.0970367)

Le Corre S, Segu L, Caldani M \& Chemineau P 1994 Differences in ketanserin binding in the ventromedial hypothalamus of ewes responsive or refractory to short days. Neuroendocrinology 60 589-600. (doi:10.1159/ 000126802) 
Lincoln GA \& Wu FCW 1991 Luteinizing hormone response to N-methylD,L-aspartate during a photoperiodically-induced reproductive cycle in the ram. Journal of Neuroendocrinology 3 309-317. (doi:10.1111/j.1365-2826. 1991.tb00280.x)

Meyer SL \& Goodman RL 1985 Neurotransmitters involved in mediating the steroid dependent suppression of pulsatile luteinizing hormone secretion in anestrous ewes: effects of receptor antagonists. Endocrinology 116 2054-2061. (doi:10.1210/endo-116-5-2054)

Meyer SL \& Goodman RL 1986 Separate neural systems mediate the steroiddependent and steroid-independent suppression of tonic luteinizing hormone secretion in the anoestrus ewe. Biology of Reproduction 35 562-571. (doi:10.1095/biolreprod35.3.562)

Meza-Herrera CA, López-García MA, López-Medrano JI, Torres-Moreno M \& Salinas-González H 2007a Excitatory aminoacids, body condition, scrotal circumference and $\mathrm{LH}$ serie concentrations in male goats under long photoperiods. Revista Chapingo Serie Zonas Aridas 6 205-210.

Meza-Herrera CA, López-Medrano JI, Torres-Moreno M, Tinajero Pérez K, Mellado-Bosque M \& González de Bulnes A $2007 b$ Excitatory amino acid effects upon the onset of puberty in goats: quantification of progesterone as endocrine marker of puberty. Revista Chapingo Serie Zonas Aridas $\mathbf{6}$ 197-203.

Meza-Herrera CA, Hallford D, Ortiz JA, Cuevas RA, Sanchez JM, Salinas H, Mellado M \& González-Bulnes A 2008 Body condition and protein supplementation positively affect periovulatory ovarian activity by non LH-mediated pathways in goats. Animal Reproduction Science 106 412-420. (doi:10.1016/j.anireprosci.2007.06.004)

Misztal T \& Romanowicz K 2005 Effective stimulation of daily LH secretion by the combined treatment with melatonin and naloxone in luteal-phase ewes. Acta Neurobiologiae Experimentalis 65 1-9.

Morand-Fehr P \& Sauvant D 1988 Alimentation des caprins. In Alimentation des Bovins, Ovins et Caprins, pp 281-304. Ed. R Jarrige. Paris: INRA.

Rhind SM 1992 Nutrition: its effect on reproductive performance and its control in female sheep and goats. In Progress in Sheep and Goats Research, pp 25-52. Ed. AW Speedy. Wallingford, UK: CAB International.

Rhind SM, McMillen SR \& McKelvey WAC 1991 Effects of levels of food intake and body condition on the sensitivity of the hypothalamus and pituitary to ovarian steroid feedback in ovariectomized ewes. Animal Production 52 115-125. (doi:10.1017/S0003356100005742)

Robinson JJ, Wigzell S, Aitken RP, Wallace JM, Ireland S \& Robertson IS 1991 The modifying effects of melatonin, mm exposure and plane of nutrition on the onset of ovarian activity, ovulation rate and the endocrine status of ewes. Animal Reproduction Science 26 73-91. (doi:10.1016/03784320(91)90067-A)

Rondón Z, Forcada F, Zarazaga L, Abecia JA \& Lozano JM 1996 Oestrous activity, ovulation rate and plasma melatonin concentrations in Rasa Aragonesa ewes maintained at two different and constant body condition levels and implanted or reimplanted with melatonin. Animal Reproduction Science 41 225-236. (doi:10.1016/0378-4320(95)01451-9)

Statistical Package for the Social Sciences (SPSS) 2008. SPSS Statistics Base User's Guide 17.0. Chicago: SPSS Inc. p. 640.

Tillet Y, Ravault JP, Selve C, Evin G, Castro B \& Dubois MP 1986 Conditions d'utilisation d'anticorps spécifiques pour la visualisation immunohistochimique de la sérotonine et de la mélatonine dans la glande pinéale du mouton. Comptes Rendus de l'Académie des Sciences 303 77-82.

Vázquez MI, Forcada F, Casao A, Sosa C, Palacín I \& Abecia JA 2009 Effects of melatonin and undernutrition on the viability of ovine embryos during anestrus and the breeding season. Animal Reproduction Science 112 83-94. (doi:10.1016/j.anireprosci.2008.04.004)

Vázquez MI, Forcada F, Casao A, Abecia JA, Sosa C \& Palacín I 2010 Undernutrition and exogenous melatonin can affect the in vitro developmental competence of ovine oocytes on a seasonal basis. Reproduction in Domestic Animals 45 677-684. (doi:10.1111/j.1439-0531.2008.01329.x)

Viguié C, Caraty A, Locatelli A \& Malpaux B 1995a Regulation of LHRH secretion by melatonin in the ewe. I. Simultaneous delayed increase in LHRH and LH pulsatile secretion. Biology of Reproduction 52 1114-1120. (doi:10.1095/biolreprod52.5.1114)

Viguié C, Caraty A, Locatelli A \& Malpaux B 1995b Regulation of luteinizing hormone-releasing hormone (LHRH) secretion by melatonin in the ewe. II. Changes in N-methyl-D,L-aspartic acid-induced LHRH release during the stimulation of luteinizing hormone secretion by melatonin. Biology of Reproduction 52 1156-1161. (doi:10.1095/biolreprod52.5.1156)

Walkden-Brown SW, Restall BJ, Norton BW, Scaramuzzi RJ \& Martin GB 1994 Effect of nutrition on seasonal patterns of LH, FSH and testosterone concentration, testicular mass, sebaceous gland volume and odour in Australian cashmere goats. Journal of Reproduction and Fertility 102 351-360. (doi:10.1530/jrf.0.1020351)

Yang KP, Lamming GE, Haynes NB \& Brooks AN 1989 Failure of melatonin to influence endogenous opioid effects on $\mathrm{LH}$ secretion in the anoestrous ewe. Journal of Reproduction and Fertility 85 397-403. (doi:10.1530/jrf.0. 0850397)

Zarazaga LA, Guzmán JL, Domínguez C, Pérez MC \& Prieto R 2005 Effect of plane of nutrition on seasonality of reproduction in Spanish Payoya goats. Animal Reproduction Science 87 253-267. (doi:10.1016/j.anireprosci.2004.11.004)

Zarazaga LA, Gatica MC, Celi I, Guzmán JL \& Malpaux B 2009 Effect of melatonin implants on sexual activity in Mediterranean goat females without separation from males. Theriogenology 72 910-918. (doi:10.1016/j. theriogenology.2009.05.020)

Zarazaga LA, Celi I, Guzmán JL \& Malpaux B 2011 a The role of nutrition in the regulation of $\mathrm{LH}$ secretion by the opioidergic, dopaminergic and serotonergic systems in female Mediterranean goats. Biology of Reproduction 84 447-454. (doi:10.1095/biolreprod.110.086520)

Zarazaga LA, Celi I, Guzmán JL \& Malpaux B $2011 b$ The response of luteinizing hormone secretion to photoperiod is modified by the level of nutrition in female Mediterranean goats. Animal Reproduction Science 126 83-90. (doi:10.1016/j.anireprosci.2011.04.017)

Received in final form 5 August 2011

Accepted 6 September 2011

Made available online as an Accepted Preprint

8 September 2011 